\title{
Enteric absorption and pharmacokinetics of oseltamivir in critically ill patients with pandemic (H1N1) influenza
}

\author{
Robert E. Ariano PharmD, Daniel S. Sitar PhD, Sheryl A. Zelenitsky PharmD, Ryan Zarychanski MD, \\ Amarnath Pisipati MSc, Stéphane Ahern MD, Salmaan Kanji PharmD, Jordi Rello MD, \\ Anand Kumar MD
}

Previously published at www.cmaj.ca

\section{ABSTRACT}

Background: Whether the enteric absorption of the neuraminidase inhibitor oseltamivir is impaired in critically ill patients is unknown. We documented the pharmacokinetic profile of oseltamivir in patients admitted to intensive care units (ICUs) with suspected or confirmed pandemic (H1N1) influenza.

Methods: We included 41 patients 18 years of age and older with suspected or confirmed pandemic (H1N1) influenza who were admitted for ventilatory support to nine ICUs in three cities in Canada and Spain. Using tandem mass spectrometry, we assessed plasma levels of oseltamivir free base and its active metabolite carboxylate at baseline (before gastric administration of the drug) and at 2, 4, 6,9 and 12 hours after the fourth or later dose.

Results: Among the 36 patients who did not require dialysis, the median concentration of oseltamivir free base was 10.4 (interquartile range [IQR] 4.8-14.9) $\mu \mathrm{g} / \mathrm{L}$; the median concentration of the carboxylate metabolite was 404 (IQR 257-900) $\mu \mathrm{g} / \mathrm{L}$. The volume of distribution of the carboxylate metabolite did not increase with increasing body weight $\left(R^{2}=0.00, p=0.87\right)$. The rate of elimination of oseltamivir carboxylate was modestly correlated with estimations of creatinine clearance $\left(R^{2}=0.27, p<0.001\right)$. Drug clearance in the five patients who required continuous renal replacement therapy was about one-sixth that in the 36 patients with relatively normal renal function.

Interpretation: Oseltamivir was well absorbed enterically in critically ill patients admitted to the ICU with suspected or confirmed pandemic (H1N1) influenza. The dosage of $75 \mathrm{mg}$ twice daily achieved plasma levels that were comparable to those in ambulatory patients and were far in excess of concentrations required to maximally inhibit neuraminidase activity of the virus. Adjustment of the dosage in patients with renal dysfunction requiring continuous renal replacement therapy is appropriate; adjustment for obesity does not appear to be necessary.

A substantial number of cases of pandemic (H1N1) influenza have involved young adults and adolescents without serious comorbidities who present with severe viral pneumonia complicated by acute respiratory distress syndrome, rhabdomyolysis, renal failure and, occasion- ally, shock. ${ }^{1,2}$ Antiviral therapy in such critically ill patients typically requires oral or nasogastric administration of the neuraminidase inhibitor oseltamivir. Current guidelines from the World Health Organization for the pharmacologic management of progressive or severe pandemic (H1N1) influenza recommend the consideration of high-dose therapy $(\geq 150 \mathrm{mg}$ twice daily) ${ }^{3,4}$ Critically ill patients exhibit defects in gastrointestinal absorption because of impaired gut perfusion, edema of the bowel wall and ileus as a consequence of critical illness and shock. ${ }^{5}$ Whether the enteric absorption of oseltamivir is impaired in such patients is unknown.

We undertook this study to document the pharmacokinetic profile of oseltamivir administered orally or by nasogastric tube in patients admitted to intensive care units (ICUs) with respiratory failure due to suspected or confirmed pandemic (H1N1) influenza.

\section{Methods}

\section{Study population}

We included patients 18 years of age and older who were admitted to nine ICUs in community and teaching hospitals located in three cities (Winnipeg, Manitoba; Ottawa, Ontario; and Tarragona, Spain). Eligible patients were those who had clinically suspected or laboratory-confirmed pandemic (H1N1) influenza associated with severe respiratory failure (necessitating ventilator support) with new pulmonary infiltrates. Confirmed cases were those in which respiratory sections were found to be positive for the virus by means of polymerase chain reaction. The study protocol received

From the Department of Pharmacy (Ariano, Zelenitsky), St. Boniface General Hospital, Winnipeg, Man.; the Department of Pharmacology and Therapeutics (Ariano, Sitar, Pisipati, Kumar), the Clinical Pharmacology Section, Department of Internal Medicine (Sitar), the Faculty of Pharmacy (Ariano, Zelenitsky), and the Sections of Critical Care Medicine and Infectious Diseases (Kumar), University of Manitoba, Winnipeg, Man.; the Department of Medical Oncology and Hematology (Zarychanski), Cancercare Manitoba, Winnipeg, Man.; Hôpital Rosemont-Maissonneuve (Ahern), Montréal, Que. the Department of Pharmacy (Kanji), The Ottawa Hospital, Ottawa, Ont.; the Critical Care Department (Rello), Hospital Universitali Joan XXIII CIBER Enfermedades Respiratorias, Universitat Rovira i Virgili, Tarragona, Spain; and the Section of Critical Care Medicine (Kumar), Cooper Hospital/University Medical Center, Camden, USA

CMAJ 2010. DOI:10.1503/cmaj.092127 
approval from the University of Manitoba Health Ethics Board and the research ethics boards of each participating institution. Informed consent was obtained from each patient or their substitute decision-maker.

\section{Pharmacologic treatment}

All patients were initially prescribed oseltamivir at a dose determined by their attending physician. In most cases, the standard adult dose of $75 \mathrm{mg}$ twice daily was used. Occasionally the physician prescribed a dose of $150 \mathrm{mg}$ twice daily based on clinical judgment.

For each dose of 75 or $150 \mathrm{mg}$, the powder from the capsule was dissolved in 5-20 mL of sterile water at room temperature and injected down the nasogastric or nasojejunal tube, followed by a water flush. Standard supportive treatment was provided as clinically indicated. Clinical and physiologic data were collected for each patient at the time of admission to ICU and on the day that blood samples were drawn for measurement of oseltamivir levels.

\section{Pharmacokinetic analysis}

Blood samples were obtained at baseline (before gastric administration of the drug) and at 2, 4, 6, 9 and 12 hours after receipt of the fourth or later dose. Plasma levels of oseltamivir free base and its active metabolite carboxylate were measured by means of high-performance liquid chromatography with tandem mass spectrometry, as previously described. ${ }^{6}$ The lower limit of detection was $1.0 \mu \mathrm{g} / \mathrm{L}$ for oseltamivir free base and $10 \mu \mathrm{g} / \mathrm{L}$ for the carboxylate metabolite.

We performed standard compartmental modelling to char-

Table 1: Characteristics of 41 critically ill patients admitted to intensive care unit with suspected or confirmed pandemic (H1N1) influenza

\begin{tabular}{lc}
\hline Characteristic & Value \\
\hline Female sex, no. (\%) & $26(63)$ \\
\hline Age, yr, mean (SD) & $41(13)$ \\
\hline Body weight, kg, mean (SD) & $99(34)$ \\
\hline Height, cm, mean (SD) & $166(12)$ \\
\hline Body mass index, mean (SD) & $36.0(11.1)$ \\
\hline APACHE Il score, mean (SD) & $19.4 \quad(6.3)$ \\
\hline Plasma creatinine level, $\mu$ mol/L, median (IQR) & $65(50-123)$ \\
\hline $\begin{array}{l}\text { Normalized creatinine clearance, } \\
\text { mL/min per 1.73 m², median (IQR) }\end{array}$ & $114(64-135)$ \\
\hline CRRT dialysis or renal failure, no. (\%) & $7(17)$ \\
\hline $\begin{array}{l}\text { Confirmed pandemic (H1N1) influenza, } \\
\text { no. (\%) }\end{array}$ & $26(63)$ \\
\hline $\begin{array}{l}\text { Days in hospital, median (IQR) } \\
\text { In-hospital mortality, no. (\%) }\end{array}$ & $16(10-30)$ \\
\hline $\begin{array}{l}\text { Receiving vasopressors at time of study, } \\
\text { no. (\%) }\end{array}$ & $13(17)$ \\
\hline $\begin{array}{l}\text { Tube feeding required at time of study, } \\
\text { no. (\%) }\end{array}$ & $30(73)$ \\
\hline
\end{tabular}

Note: CCRT = continuous renal replacement therapy, IQR = interquartile range, $\mathrm{SD}=$ standard deviation. acterize the pharmacokinetics of oseltamivir after gastric administration. We performed this analysis using the nonlinear least-squares fitting program, ADAPT- $5,{ }^{7}$ assuming a onecompartment open model with first-order absorption and elimination for complete conversion of oseltamivir free base to its carboxylate metabolite. We determined the overall error pattern of the assay for oseltamivir free base and the carboxylate metabolite by fitting a polynomial to the plot of the assay's standard deviations (SDs) versus plasma concentrations.

Using the ADAPT fitting routine, we weighted each plasma concentration to the iterated modelled concentration by the reciprocal of the assay's error variance (i.e., $1 / \mathrm{SD}^{2}$ ). The pharmacokinetic parameters identified were the absorption rate constant from the gastrointestinal tract, the metabolic conversion from oseltamivir free base to its carboxylate metabolite (i.e., assuming complete conversion), the elimination rate constant of the metabolite, and the apparent volume of distribution of oseltamivir free base and of the carboxylate metabolite. To examine renal function as a covariate with pharmacokinetic parameters, we used creatinine clearance as determined by the normalized Cockcroft-Gault equation, where creatinine clearance $\left[\mathrm{mL} / \mathrm{min}\right.$ per $\left.1.73 \mathrm{~m}^{2}\right]=(140-$ age $) \times 88.4 /$ plasma creatinine $[\mu \mathrm{mol} / \mathrm{L}]$, multiplied by $85 \%$ for females. ${ }^{8}$

Using an approach previously validated by Wattanagoon and colleagues, ${ }^{9}$ we performed dose normalization of pharmacokinetic parameters and concentrations to allow for comparative inclusion of patients who received the nonstandard regimen of $150 \mathrm{mg}$ twice daily. We compared parameters of clinical outcomes, such as duration of hospital stay and survival, using actual drug concentration and area-under-thecurve values for whichever regimen the patient was receiving. All statistical tests used a two-tailed $p$ value of less than 0.05 to indicate a significant difference between groups.

[The methods are described in further detail in Appendix 1, available at www.cmaj.ca/cgi/content/full/cmaj.092127/DC1.]

\section{Results}

We enrolled 44 critically ill patients with suspected or confirmed pandemic (H1N1) influenza who were admitted to ICU because of respiratory failure. Two of the patients were studied twice (one was studied at two different doses of oseltamivir, and the other was studied before and after initiation of continous renal replacement therapy), for a total of 46 data sets for pharmacokinetic analysis. We dropped three data sets because we were unable to fit the pharmacokinetic model to the data. This left 43 pharmacokinetic analyses from 41 patients.

Characteristics of the 41 patients are shown in Table 1 . We found no significant difference in patient characteristics between the 36 patients who did not require dialysis (the primary study cohort) and the 5 patients who required continous renal replacement therapy. Of the 43 pharmacokinetic analyses, $14(33 \%)$ showed evidence of moderate, and $8(19 \%)$ severe, renal dysfunction (normalized creatinine clearance $<50$ and $<30 \mathrm{~mL} / \mathrm{min}$ per $1.73 \mathrm{~m}^{2}$, respectively). Seven of the eight patients with severe renal dysfunction had sufficiently severe (end-stage) renal injury to require dialysis; five were receiving continous renal replacement therapy at the time of 
the pharmacokinetic assessment; the other two were temporarily off dialysis at the time of the assessment (Table 2). Of the seven patients who died, six $(86 \%)$ had laboratoryconfirmed pandemic (H1N1) influenza. The deaths involved 2 of the 7 patients with renal failure and 5 of the 34 patients in the primary study cohort. Overall, $30(73 \%)$ of the patients were receiving continuous enteral feeding, and $13(32 \%)$ were receiving vasopressor therapy through the time that oseltamivir assay samples were obtained (Table 2).

Median values and interquartile ranges from the pharma-

Table 2: Results of 43 pharmacokinetic analyses for oseltamivir free base and its active carboxylate metabolite in 41 critically ill patients with suspected or confirmed pandemic (H1N1) influenza

\begin{tabular}{|c|c|c|c|c|c|c|c|}
\hline \multirow[b]{2}{*}{ Parameter } & \multicolumn{3}{|c|}{$\begin{array}{l}\text { Renal function; } \\
\text { median (IQR) }\end{array}$} & \multicolumn{2}{|c|}{$\begin{array}{l}\text { Vasopressor therapy; } \\
\text { median (IQR) }\end{array}$} & \multicolumn{2}{|c|}{$\begin{array}{l}\text { Tube feeding;§ } \\
\text { median (IQR) }\end{array}$} \\
\hline & $\begin{array}{l}\text { Normal } \\
n=36\end{array}$ & $\begin{array}{c}\text { Renal dysfunction, } \\
\text { CRRT received } \\
n=5\end{array}$ & $\begin{array}{c}\text { Renal dysfunction, } \\
\text { no dialysis } \\
n=2\end{array}$ & $\begin{array}{l}\text { Prescribed } \\
\quad n=13\end{array}$ & $\begin{array}{l}\text { Not prescribed } \\
\quad n=22\end{array}$ & $\begin{array}{c}\text { Present } \\
n=30\end{array}$ & $\begin{array}{l}\text { Absent } \\
n=11\end{array}$ \\
\hline $\begin{array}{l}\text { Half-life of absorption } \\
\text { of oseltamivir free base } \\
\text { across gastrointestinal } \\
\text { tract, } h\end{array}$ & $\begin{array}{c}2.2 \\
(1.6-3.8)\end{array}$ & $\begin{array}{c}3.5 \\
(3.2-4.3)\end{array}$ & $1.6,2.6$ & $\begin{array}{c}3.5 \\
(2.2-4.5)\end{array}$ & $\begin{array}{c}2.3 \\
(1.4-3.7)\end{array}$ & $\begin{array}{c}2.9 \\
(1.9-3.8)\end{array}$ & $\begin{array}{c}1.8 \\
(1.4-3.6)\end{array}$ \\
\hline $\begin{array}{l}\text { Time to peak plasma } \\
\text { concentration, min }\end{array}$ & $\begin{array}{c}30 \\
(22-36)\end{array}$ & $\begin{array}{c}34 \\
(19-40)\end{array}$ & 267,46 & $\begin{array}{c}64 \\
(29-65)\end{array}$ & $\begin{array}{c}27 \\
(18-36)\end{array}$ & $\begin{array}{c}33 \\
(22-36)\end{array}$ & $\begin{array}{c}27 \\
(22-45)\end{array}$ \\
\hline $\begin{array}{l}\text { Half-life of metabolic } \\
\text { carboxylation of } \\
\text { oseltamivir from free } \\
\text { base, min }\end{array}$ & $\begin{array}{c}6.4 \\
(4.2-7.4)\end{array}$ & $\begin{array}{c}6.2 \\
(3.2-7.1)\end{array}$ & 48,11 & $\begin{array}{c}6.8 \\
(6.2-11.3)\end{array}$ & $\begin{array}{c}5.9 \\
(3.5-7.1)\end{array}$ & $\begin{array}{c}6.5 \\
(4.1-7.5)\end{array}$ & $\begin{array}{c}6.7 \\
(4.4-14.2)\end{array}$ \\
\hline $\begin{array}{l}\text { Half-life of elimination of } \\
\text { oseltamivir carboxylate } \\
\text { from plasma, h }\end{array}$ & $\begin{array}{c}6.1 \\
(4.9-12.2)\end{array}$ & $\begin{array}{c}13 \\
(8.1-18.3)\end{array}$ & 101,59 & $\begin{array}{c}11.3 \\
(6.1-28.0)\end{array}$ & $\begin{array}{c}5.8 \\
(4.7-11.7)\end{array}$ & $\begin{array}{c}6.5 \\
(5.2-15.3)\end{array}$ & $\begin{array}{c}10.4 \\
(4.3-33.1)\end{array}$ \\
\hline \multicolumn{8}{|l|}{$\begin{array}{l}\text { Volume of } \\
\text { distribution, L/F }\end{array}$} \\
\hline $\begin{array}{l}\text { Oseltamivir } \\
\text { free base }\end{array}$ & $\begin{array}{c}89 \\
(63-206)\end{array}$ & $\begin{array}{c}97 \\
(85-149)\end{array}$ & 443,61 & $\begin{array}{c}139 \\
(83-304)\end{array}$ & $\begin{array}{c}74 \\
(61-131)\end{array}$ & $\begin{array}{c}89 \\
(69-210)\end{array}$ & $\begin{array}{c}75 \\
(61-184)\end{array}$ \\
\hline $\begin{array}{l}\text { Oseltamivir } \\
\text { carboxylate }\end{array}$ & $\begin{array}{c}148 \\
(89-234) \uparrow\end{array}$ & $\begin{array}{c}37 \\
(32-64)\end{array}$ & 276,96 & $\begin{array}{c}114 \\
(69-217)\end{array}$ & $\begin{array}{c}143 \\
(82-252)\end{array}$ & $\begin{array}{c}115 \\
(71-239)\end{array}$ & $\begin{array}{c}136 \\
(93-179)\end{array}$ \\
\hline \multicolumn{8}{|l|}{ Clearance, L/h/F } \\
\hline $\begin{array}{l}\text { Oseltamivir } \\
\text { free base }\end{array}$ & $\begin{array}{c}778 \\
(457-1252)\end{array}$ & $\begin{array}{c}571 \\
(568-2137)\end{array}$ & 507,307 & $\begin{array}{c}701 \\
(491-1704)\end{array}$ & $\begin{array}{c}696 \\
(413-1181)\end{array}$ & $\begin{array}{c}851 \\
(501-1560)\end{array}$ & $\begin{array}{c}516 \\
(328-675)\end{array}$ \\
\hline $\begin{array}{l}\text { Oseltamivir } \\
\text { carboxylate }\end{array}$ & $\begin{array}{c}13.9 \\
(6.0-21.7)\end{array}$ & $\begin{array}{c}2.4 \\
(2.4-4.4)\end{array}$ & $2.5,1.5$ & $\begin{array}{c}4.7 \\
(2.4-15.5)\end{array}$ & $\begin{array}{c}13.0 \\
(6.0-22.3)\end{array}$ & $\begin{array}{c}12.1 \\
(5.0-19.7)\end{array}$ & $\begin{array}{c}10.7 \\
(3.0-25.2)\end{array}$ \\
\hline $\begin{array}{l}\text { Oseltamivir } \\
\text { carboxylate in } \\
\text { patients with normal } \\
\text { renal function }\end{array}$ & $\begin{array}{c}14.1 \\
(6.6-21.6)^{* *}\end{array}$ & NA & NA & NA & NA & NA & NA \\
\hline \multicolumn{8}{|l|}{$\begin{array}{l}\text { Area under the curve, } \\
\text { normalized, }{ }^{*} \mu \mathrm{g} \cdot \mathrm{h} / \mathrm{L}\end{array}$} \\
\hline $\begin{array}{l}\text { Oseltamivir } \\
\text { free base }\end{array}$ & $\begin{array}{c}98 \\
(60-166)\end{array}$ & $\begin{array}{c}131 \\
(35-132)\end{array}$ & 148,244 & $\begin{array}{c}107 \\
(45-153)\end{array}$ & $\begin{array}{c}108 \\
(63-182)\end{array}$ & $\begin{array}{c}89 \\
(48-150)\end{array}$ & $\begin{array}{c}145 \\
(112-229)\end{array}$ \\
\hline $\begin{array}{l}\text { Oseltamivir } \\
\text { carboxylate }\end{array}$ & $\begin{array}{c}4854 \\
(3 \quad 109-10820)+\dagger\end{array}$ & $\begin{array}{c}28023 \\
(15617-28848)\end{array}$ & 27363,45864 & $\begin{array}{c}14499 \\
(4488-28229)\end{array}$ & $\begin{array}{c}4958 \\
(3042-8712)\end{array}$ & $\begin{array}{c}5648 \\
(3459-13710)\end{array}$ & $\begin{array}{c}5362 \\
(2544-21677)\end{array}$ \\
\hline \multicolumn{8}{|l|}{$\begin{array}{l}\text { Average plasma } \\
\text { concentration during } 12-\mathrm{h} \\
\text { collection period, }{ }^{*} \mu \mathrm{g} / \mathrm{L}\end{array}$} \\
\hline $\begin{array}{l}\text { Oseltamivir } \\
\text { free base }\end{array}$ & $\begin{array}{c}10.4 \\
(4.8-15.2)\end{array}$ & $\begin{array}{c}10.3 \\
(10.3-10.8)\end{array}$ & $12.4,16.7$ & $\begin{array}{c}10.3 \\
(5.3-12.7)\end{array}$ & $\begin{array}{c}10.5 \\
(4.6-18.5)\end{array}$ & $\begin{array}{c}10.3 \\
(4.5-13.7)\end{array}$ & $\begin{array}{c}14.8 \\
(9.7-18.5)\end{array}$ \\
\hline $\begin{array}{l}\text { Oseltamivir } \\
\text { carboxylate }\end{array}$ & $\begin{array}{c}404 \\
(252-901)+\dagger\end{array}$ & $\begin{array}{c}2000 \\
(1248-2337)\end{array}$ & 573,2722 & $\begin{array}{c}683 \\
(367-2084)\end{array}$ & $\begin{array}{c}407 \\
(240-941)\end{array}$ & $\begin{array}{c}459 \\
(277-941)\end{array}$ & $\begin{array}{c}401 \\
(223-1827)\end{array}$ \\
\hline $\begin{array}{l}\text { Trough plasma } \\
\text { concentration during } \\
\text { dosing interval, }{ }^{*} \mu \mathrm{g} / \mathrm{L}\end{array}$ & $\begin{array}{c}282 \\
(140-749)+\dagger\end{array}$ & $\begin{array}{c}1170 \\
(1170-1890)\end{array}$ & 478,2440 & $\begin{array}{c}514 \\
(268-1350)\end{array}$ & $\begin{array}{c}282 \\
(126-730)\end{array}$ & $\begin{array}{c}337 \\
(145-767)\end{array}$ & $\begin{array}{c}284 \\
(159-1380)\end{array}$ \\
\hline
\end{tabular}

Note: $\mathrm{CRRT}=$ continuous renal replacement therapies, $\mathrm{F}=$ systemic bioavailability, IQR = interquartile range, NA = not applicable;

*The area under the curve and average concentrations have been normalized to a dosage of 75 mg twice daily. Eight patients ( $22 \%$ ) received a regimen of 150 mg twice daily. Reported average concentrations are not necessarily comparative steady-state values, especially for patients who had renal dysfunction.

tTwo patients with renal dysfunction were temporarily off of CRRT at the time of the pharmacokinetic assessment. Actual values for these two patients are provided. fIncluded norepinephrine, phenylephrine, dopamine and vasopressin. Data on vasopressors were missing for eight analyses.

$\S$ Data on tube feeding were missing for two analyses.

I $p=0.002$.

${ }^{* *} p=0.002$ for comparison of clearance of oseltamivir carboxylate in patients with normal renal function versus patients receiving CRRT.

$\dagger+p<0.001$. 
cokinetic analyses are shown in Table 2. Figure 1 shows the average plasma concentrations of the carboxylate metabolite over one dosing interval in the 36 patients who did not require dialysis, with the dose normalized to $75 \mathrm{mg}$ twice daily. These plasma concentrations were usually obtained after the second or third day of oseltamivir therapy at anticipated steady state (for patients with relatively normal renal function). Figure 2 shows the average plasma concentrations in the five patients who received continuous renal replacement therapy, again with the dose normalized to $75 \mathrm{mg}$ twice daily. The average concentration was five times higher in the dialysis group than in the primary study group based on a dosing regimen of $75 \mathrm{mg}$ twice daily (2000 v. $404 \mu \mathrm{g} / \mathrm{L}, p<0.001)$.

The median trough plasma concentration of the carboxylate metabolite was also five times higher in the dialysis group than in the primary study group (1170 v. $282 \mu \mathrm{g} / \mathrm{L}, p<$ 0.001 ) (Table 2). The lowest recorded trough concentration of oseltamivir carboxylate was $55 \mu \mathrm{g} / \mathrm{L}$ in the primary study group, as compared with $1045 \mu \mathrm{g} / \mathrm{L}$ in the dialysis group, with a dosing regimen of $75 \mathrm{mg}$ twice daily.

The overall median plasma levels and median trough plasma levels of oseltamivir were similar in patients given vasopressors compared with those not given vasopressors, and in patients fed enterally compared with those not fed enterally (Table 2).

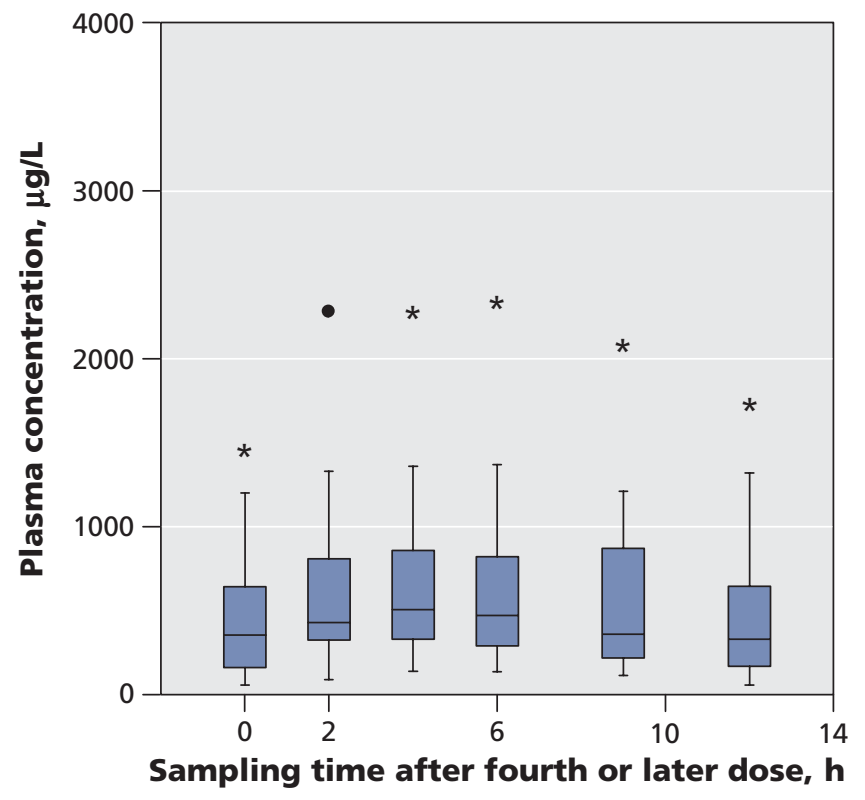

Figure 1: Average plasma concentrations of oseltamivir carboxylate over one dosing interval in 34 patients admitted to intensive care unit (ICU) with suspected or confirmed pandemic (H1N1) influenza who did not require dialysis (primary study cohort). Oseltamivir doses were normalized to $75 \mathrm{mg}$ twice daily. The horizontal line in the middle of each box indicates the median, and the top and bottom borders of the box mark the 25th and 75th percentiles, respectively. The whiskers are 1.5 times the upper and lower interquartile ranges. The outlier (black dot) indicates a case with values between 1.5 and 3 box lengths from one side of the range. The extreme values (*) indicate cases with values more than 3 box lengths from the 75th or 25th percentile.
The absorption half-life of oseltamivir was 2.2 hours in the primary study group, as compared with 3.5 hours in the dialysis group $(p=0.25)$ (Table 2). Four patients had evidence of substantial delays to peak oral absorption of oseltamivir of 1.0 or more hours. Most patients had a peak concentration of the parent compound within 30 minutes of nasogastric administration. A prolonged half-life of absorption in patients given vasopressors failed to reach statistical significance ( 3.5 hours v. 2.3 hours in patients not given vasopressors, $p=0.06$ ).

We examined a number of patient covariates for associations with pharmacokinetic parameters (Table 3). We found no association between body weight and the volume of distribution for oseltamivir carboxylate $\left(R^{2}=0.01, p=0.87\right.$, Table 3 , Figure 3 ) or between body weight and the normalized area under the curve for oseltamivir carboxylate $\left(R^{2}=0.00, p=\right.$ 0.96 , Table 3). We did find an association between normalized creatinine clearance and the elimination rate of the carboxylate metabolite $\left(R^{2}=0.27, p<0.001\right.$, Table 3 and Figure 4).

With regard to associations between clinical outcomes and pharmacokinetic parameters, we did not find a significant relation between the duration of hospital stay and the plasma trough concentrations of oseltamivir carboxylate $\left(R^{2}=0.16\right.$, $p=0.06$ ) (see Appendix 2, available at www.cmaj.ca/cgi /content/full/cmaj.092127/DC1). Measured trough concentrations and area-under-the-curve values for the carboxylate metabolite did not correspond with improved survival in the

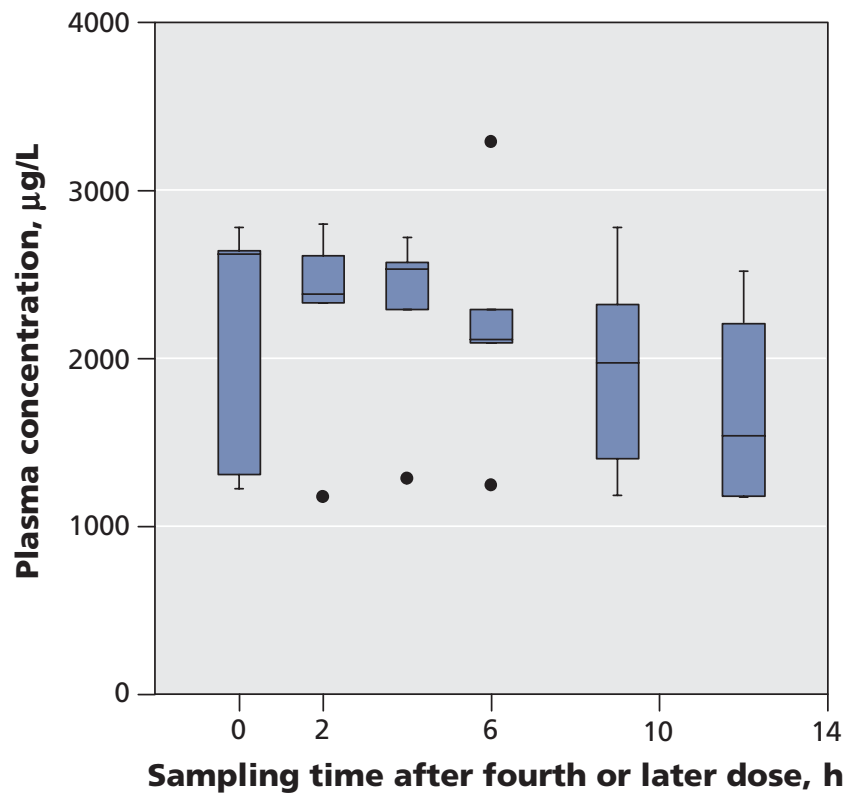

Figure 2: Average plasma concentrations of oseltamivir carboxylate over one dosing interval in five patients admitted to ICU with suspected or confirmed pandemic (H1N1) influenza who received continuous renal replacement therapy. Oseltamivir doses were normalized to $75 \mathrm{mg}$ twice daily. The horizontal line in the middle of each box indicates the median, and the top and bottom borders of the box mark the 25th and 75th percentiles, respectively. The whiskers are 1.5 times the upper and lower interquartile ranges. The outlier (black dot) indicates a case with values between 1.5 and 3 box lengths from one side of the range. 
Table 3: Correlations between patient characteristics and pharmacokinetic parameters for oseltamivir

\begin{tabular}{lcc}
\hline Correlation & $R^{2}$ & $p$ value \\
\hline $\begin{array}{l}\text { Body weight v. volume of distribution } \\
\text { for oseltamivir free base }\end{array}$ & 0.01 & 0.94 \\
$\begin{array}{l}\text { Body weight v. volume of distribution } \\
\text { for oseltamivir carboxylate }\end{array}$ & 0.01 & 0.87 \\
$\begin{array}{l}\text { Body weight v. clearance of oseltamivir } \\
\text { free base }\end{array}$ & 0.06 & 0.07 \\
$\begin{array}{l}\text { Body weight v. clearance of oseltamivir } \\
\text { carboxylate }\end{array}$ & 0.02 & 0.35 \\
$\begin{array}{l}\text { Body weight v. normalized area under } \\
\text { the curve for oseltamivir carboxylate }\end{array}$ & 0.00 & 0.96 \\
$\begin{array}{l}\text { Creatinine clearance calculated on the } \\
\text { basis of absolute body weight v. } \\
\text { elimination constant for oseltamivir } \\
\text { carboxylate }\end{array}$ & 0.23 & 0.01 \\
$\begin{array}{l}\text { Creatinine clearance calculated on the } \\
\text { basis of ideal body weight v. elimination } \\
\text { constant for oseltamivir carboxylate }\end{array}$ & 0.23 & 0.001 \\
\hline $\begin{array}{l}\text { Normalized creatinine clearance v. } \\
\text { elimination constant for oseltamivir } \\
\text { carboxylate }\end{array}$ & 0.27 & $<0.001$ \\
\hline
\end{tabular}

primary study group (see Appendix 3, available at www.cmaj .ca/cgi/content/full/cmaj.092127/DC1).

\section{Interpretation}

Our results show that the median and trough plasma concentrations of the active carboxylate metabolite of oseltamivir in critically ill patients in our study who did not require dialysis (primary study group) were similar or higher than values achieved at steady state in other clinical trials involving ambulatory patients given multiple doses of oseltamivir $75 \mathrm{mg}$ twice daily. ${ }^{9-15}$ Although there was some delay in the gastrointestinal absorption of the drug after nasogastric or nasojejunal administration (Table 2), the final area under the curve for the carboxylate metabolite at the 75-mg dose in our primary study cohort was also similar to values found in ambulatory patients. ${ }^{12,13,15}$

The achieved concentration of oseltamivir in relation to the sensitivity of the influenza virus is associated with the probability of viral eradication and clinical cure in vivo. ${ }^{15,16}$ The National Microbiology Laboratory has identified the $50 \%$ maximal inhibitory concentration for oseltamivir carboxylate to be 0.090 (SD $0.046 \mu \mathrm{g} / \mathrm{L}$ using 309 isolates of the pandemic (H1N1) influenza virus (Nathalie Bastien, PhD, National Microbiology Laboratory, Public Health Agency of Canada: personal communication, 2009). Similarly, Gubareva and colleagues have documented a 50\% maximal inhibitory concentration of $0.186 \mathrm{SD} 0.107 \mu \mathrm{g} / \mathrm{L}$ for isolates of the pandemic (H1N1) influenza virus. ${ }^{17}$ In our study, the average plasma concentration of oseltamivir carboxylate was well over 2000- to 4000-fold higher than these 50\% maximal inhibitory concentrations. For the patient with the single low- est trough concentration of $55 \mu \mathrm{g} / \mathrm{L}$, this concentration was about 300- to 600-fold higher than the reported average $50 \%$ maximal inhibitory concentration for the pandemic (H1N1) influenza virus.

The $90 \%$ inhibitory concentrations are not available for isolates of the pandemic (H1N1) influenza virus. However, if one assumes a ratio between the $50 \%$ maximal inhibitory concentration and the $90 \%$ maximal inhibitory concentrations similar to those found for other influenza A viruses (i.e., about 10$),{ }^{18}$ the trough plasma values of oseltamivir carboxylate in our study were still at least 30 to 60 times greater than likely values for the $90 \%$ maximal inhibitory concentration for isolates of the pandemic (H1N1) influenza virus. Values for the area under the curve for oseltamivir carboxylate were similarly high relative to the sensitivity of the virus to the metabolite.

The dose of an antiviral drug may affect outcome if increasing levels in blood are associated with more rapid clearance of the virus from the infected host. This can occur in situations when the high 50\% maximal inhibitory concentrations of the virus place the patient on the steep portion of the pharmacodynamic response curve. In this regard, some authors have suggested a need to maintain high plasma trough concentrations or area-under-the-curve values for oseltamivir carboxylate relative to the $50 \%$ maximal inhibitory concentration of the influenza virus for optimal suppression of viral replication. ${ }^{15,19}$ In view of the documented $50 \%$ maximal inhibitory concentration of the pandemic (H1N1) influenza virus, a regimen of oseltamivir $75 \mathrm{mg}$ twice daily clearly results in trough concentrations and area-under-the-curve values for the carboxylate metabolite that are well above any likely pharmacodynamic threshold for maximal inhibition of the virus. Given this fact, it is not surprising that we found no correlation between trough plasma levels and area-under-thecurve values and main clinical outcomes (length of hospital stay and survival) (see Appendices 2 and 3, available at www .cmaj.ca/cgi/content/full/cmaj.092127/DC1). These data sug-

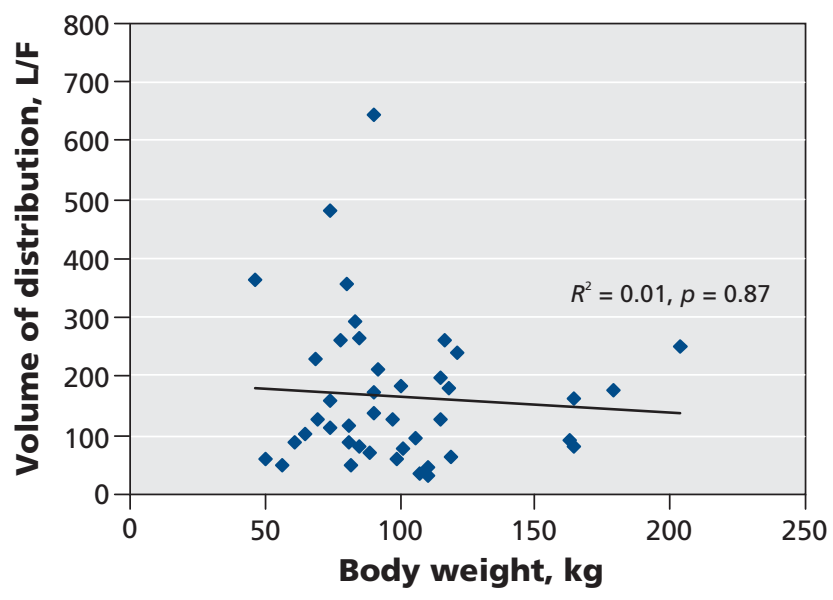

Figure 3: Scatterplot showing the relation between body weight and volume of distribution for oseltamivir carboxylate. Solid line represents the linear regression fit across all patients. $\mathrm{F}=$ systemic bioavailability. 


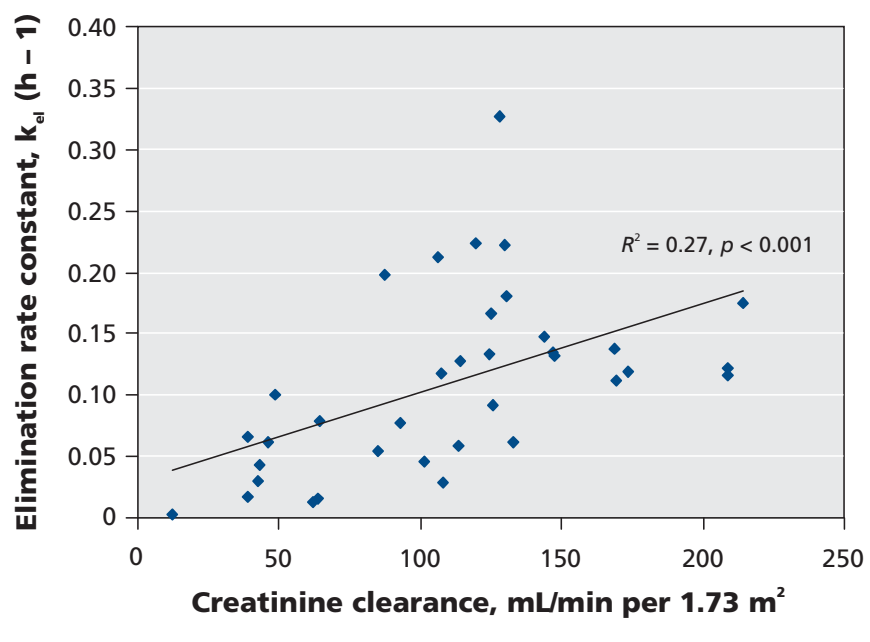

Figure 4: Scatterplot showing the relation between normalized creatinine clearance and the elimination rate of oseltamivir carboxylate. Solid line represents the linear regression fit across all patients.

gest that the standard dose of $75 \mathrm{mg}$ of oseltamivir twice daily is sufficient and that higher doses are unlikely to provide additional antiviral activity, assuming good penetration of the drug into infected lung tissue. ${ }^{20}$

We found no correlation between body weight and either the area under the curve or the volume of distribution for oseltamivir carboxylate (Table 3, Figure 3). This lack of association would suggest that altering the dose may not be necessary in critically ill adult patients whose weight is within the approximately 50- to 200-kg range of our study cohort.

Although the patients in our study had a wide range of renal function, we found only a modest correlation $\left(R^{2}=0.27\right.$, $p<0.001$ ) between the elimination rate constant of oseltamivir carboxylate and normalized creatinine clearance (Table 3, Figure 4). Creatinine clearance as calculated by either absolute or ideal body weight provided no better estimation of the rate of elimination of the metabolite than the normalized equation. The presence of only a modest correlation is not surprising, because the Cockcroft-Gault equation assumes steady-state renal function, an infrequent condition in critically ill patients. In addition, partial renal tubular secretion of oseltamivir may not be adequately reflected by simple changes in plasma creatinine levels.

Few data are available on the pharmacokinetics of oseltamivir carboxylate during continuous renal replacement therapy. ${ }^{10} \mathrm{We}$ found that clearance of the metabolite during dialysis was about one-fifth to one-sixth that of patients with relatively normal renal function. With regards to exposure to the carboxylate metabolite from the 75-mg, twice-daily regimen, the area under the curve (normalized to the 75-mg, twice-daily dose) was almost six times higher in patients receiving dialysis than in those with relatively normal renal function (Table 2). To achieve an exposure to the carboxylate metabolite in the dialysis population that is relatively equivalent to the exposure in patients with normal renal function receiving $75 \mathrm{mg}$ twice daily, either $30 \mathrm{mg}$ daily or $75 \mathrm{mg}$ every 48 hours should suffice.

\section{Limitations}

We were unable to assess whether lung injury associated with severe pneumonia due to influenza limited penetration of oseltamivir into lung tissue such that drug levels in lung tissue were suboptimal compared with blood levels. Assessment of this question would have required bronchoalveolar lavage to determine drug levels in alveolar fluid. Another limitation is that we did not assess the effect of antiviral concentrations on pulmonary viral load. This would have been a useful marker of the drug's pharmacodynamic activity, since viral clearance is the most direct benefit of oseltamivir therapy.

\section{Conclusion}

Current guidelines from the World Health Organization recommend that all patients with pandemic (H1N1) influenza should receive oseltamivir and that, in the case of progressive or severe disease, a higher dose (e.g., $150 \mathrm{mg}$ twice daily) be considered. ${ }^{3,4}$ The findings of our study suggest that a higher dose of oseltamivir is unlikely to be necessary in such cases. Blood levels of oseltamivir in the critically ill patients in our study were comparable or higher than those in ambulatory patients in previous studies who were given similar dosing regimens. Adjustment of the dosage in patients with renal dysfunction requiring continuous renal replacement therapy is appropriate; adjustment for obesity does not appear to be necessary.

This article has been peer reviewed.

Competing interests: Stéphane Ahern is President of the Comité scientifique de l'inscription, Conseil du médicament du Québec. Anand Kumar is directing another study of oseltamivir therapy for pandemic (H1N1) influenza that is supported by a research grant from Hoffmann-La Roche. No competing interests declared for Robert Ariano, Daniel Sitar, Sheryl Zelenitsky, Ryan Zarychanski, Amarnath Pisipati, Salmaan Kanji or Jordi Rello.

Contributors: Anand Kumar was responsible for the study design. Ryan Zarychanski, Amarnath Pisipati, Stéphane Ahern, Salman Kanji, Jordi Rello and Anand Kumar contributed to the collection of data and blood samples. Robert Ariano, Daniel Sitar, Sheryl Zelenitsky and Anand Kumar contributed to the analysis and interpretation of data. Robert Ariano and Anand Kumar drafted the manuscript; the remaining coauthors revised the manuscript for important intellectual content. All of the authors gave final approval of the version to be published. Robert Ariano and Anand Kumar had full access to all of the data in the study and take responsibility for the integrity of the data and the accuracy of the data analysis.

Acknowledgements: The authors gratefully acknowledge the efforts of BASi (formerly Bioanalytical Systems, Inc.) in the measurement of plasma oseltamivir levels. They also thank Wendy Janz, Nicole Marten, Mandi Siddiqui, Kym Wiebe, Davie Wong, Sandra Trefler, Dr. Martin-Loeches, Mireia Llaurado, Dr. Brian Davies and Irene Watpool for technical support.

Funding: The Public Health Agency of Canada and Hoffmann-La Roche Inc. provided grants in support of this study. Neither had any role in the study design, the collection, analysis or interpretation of data, the writing of the report, or the decision to submit the work for publication.

\section{REFERENCES}

1. Kumar A, Zarychanski R, Pinto R, et al. Critically ill patients with 2009 influenza A(H1N1) infection in Canada. JAMA 2009;302:1872-9.

2. Dominguez-Cherit G, Lapinsky SE, Espinosa-Perez L, et al. Critically ill patients with influenza A (novel H1N1) in Mexico. JAMA 2009;302:1880-7.

3. World Health Organization. WHO guidelines for pharmacologic management of pandemic (H1N1) 2009 influenza and other influenza viruses. Geneva (Switzerland): The Organization; 2009. 
4. World Health Organization. Clinical management of human infection with pandemic (H1N1) 2009: revised guidance. Geneva (Switzerland): The Organization; 2009.

5. Power BM, Forbes AM, van Heerden PV, et al. Pharmacokinetics of drugs used in critically ill adults. Clin Pharmacokinet 1998;34:25-56.

6. Wiltshire H, Wiltshire B, Citron A, et al. Development of a high-performance liquid chromatographic-mass spectrometric assay for the specific and sensitive quantification of Ro 64- 0802, an anti-influenza drug, and its pro-drug, oseltamivir, in human and animal plasma and urine. J Chromatogr B Biomed Sci Appl 2000;745:373-88.

7. D'Argenio DZ, Schumitzky A, Wang X. ADAPT 5 user guide: pharmacokinetic/ pharmacodynamic systems analysis software. Los Angeles (CA): Biomedical Simulations Resource; 2009.

8. D'Angio R, Platt DR, Gannon R. Creatinine clearance: corrected versus uncorrected. DICP 1988;22:32-3.

9. Wattanagoon Y, Stepniewska K, Lindegardh N, et al. Pharmacokinetics of high-dose oseltamivir in healthy volunteers. Antimicrob Agents Chemother 2009:53:945-52.

10. Taylor WR, Thinh BN, Anh GT, et al. Oseltamivir is adequately absorbed following nasogastric administration to adult patients with severe H5N1 influenza. PLoS One 2008;3:e3410.

11. Schentag JJ, Hill G, Chu T, et al. Similarity in pharmacokinetics of oseltamivir and oseltamivir carboxylate in Japanese and Caucasian subjects. J Clin Pharmacol 2007:47:689-96.

12. Snell P, Dave N, Wilson K, et al. Lack of effect of moderate hepatic impairment on the pharmacokinetics of oral oseltamivir and its metabolite oseltamivir carboxylate. Br J Clin Pharmacol 2005;59:598-601.

13. Abe M, Smith J, Urae A, et al. Pharmacokinetics of oseltamivir in young and very elderly subjects. Ann Pharmacother 2006;40:1724-30.
14. Massarella JW, He GZ, Dorr A, et al. The pharmacokinetics and tolerability of the oral neuraminidase inhibitor oseltamivir (Ro 64-0796/GS4104) in healthy adul and elderly volunteers. J Clin Pharmacol 2000;40:836-43.

15. He G, Massarella J, Ward P. Clinical pharmacokinetics of the prodrug oseltamivir and its active metabolite Ro 64-0802. Clin Pharmacokinet 1999;37:471-84.

16. Ward P, Small I, Smith J, et al. Oseltamivir (Tamiflu) and its potential for use in the event of an influenza pandemic. J Antimicrob Chemother 2005;55(Suppl 1):i5-21.

17. Gubareva L, Okomo-Adhiambo M, Deyde V, et al. Update: drug susceptibility of swine-origin influenza A (H1N1) viruses, April 2009. MMWR Morb Mortal Weekly Rep 2009;58:433-5.

18. Bantia S, Parker CD, Ananth SL, et al. Comparison of the anti-influenza virus activity of RWJ-270201 with those of oseltamivir and zanamavir. Antimicrob Agents Chemother 2001;45:1162-7.

19. McSharry JJ, Weng Q, Brown A, et al. Prediction of the pharmacodynamically linked variable of oseltamivir carboxylate for influenza A virus using an in vitro hollow-fibe infection model system. Antimicrob Agents Chemother 2009;53:2375-81.

20. Eisenberg EJ, Bidgood A, Cundy KC. Penetration of GS4071, a novel influenza neuraminidase inhibitor, into rat bronchoalveolar lining fluid following oral administration of the prodrug GS4104. Antimicrob Agents Chemother 1997;41:1949-52.

Correspondence to: Dr. Anand Kumar, Section of Critical Care Medicine, Health Sciences Centre, Rm. JJ 399, 700 William Ave., Winnipeg MB R3E 0Z3; akumar61@yahoo.com

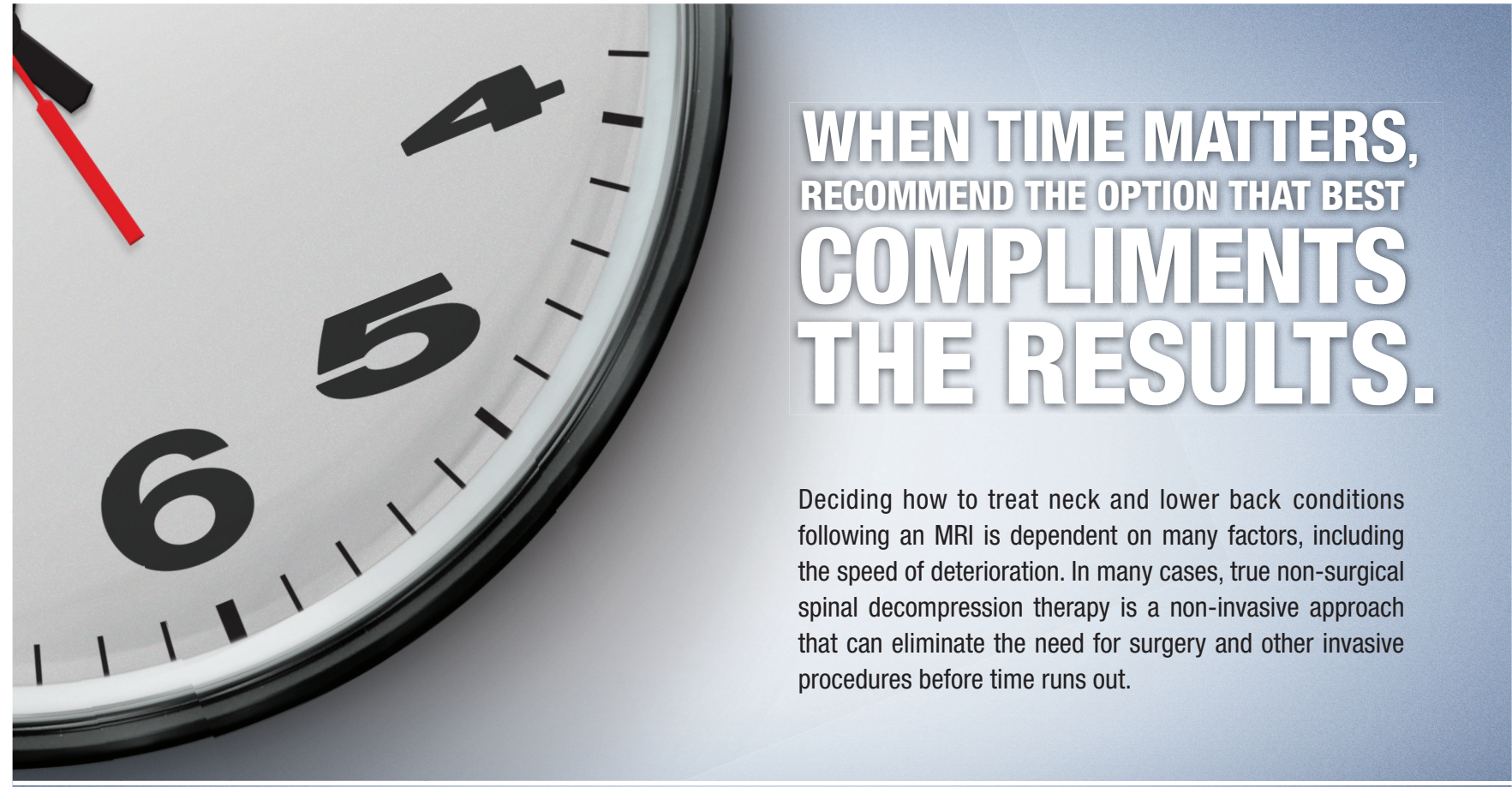

GET YOUR FREE DOGTOR KIT TODAY AT WwW.spinaldecompression kit.com Our free Information Kit will help you better determine which patients are good candidates for true non-surgical spinal decompression.
PLOW BACK CLINIC Specialized Care For Severe Neck \& Back Pain 